\title{
INTERACTION OF A LIGHT GAS STRATIFIED LAYER WITH AN AIR JET COMING FROM BELOW: LARGE SCALE EXPERIMENTS AND SCALING ISSUES
}

\author{
E. Studer ${ }^{1}$, J. Brinster, I. Tkatschenko, ${ }^{2}$ \\ G. Mignot, D. Paladino, M. Andreani ${ }^{3}$ \\ ${ }^{1}$ CEA/DEN/DANS/DM2S/SFME/LTMF 91191 Gif-sur-Yvette France, etienne.studer@cea.fr \\ ${ }^{2}$ CEA/DEN/DANS/DM2S/SFME/LEEF 91191 Gif-sur-Yvette France, \\ ${ }^{3}$ Thermal-hydraulics Laboratory Paul Scherrer Institute CH-5232 Villigen Switzerland.
}

\begin{abstract}
In the frame of the OECD/SETH-2 project, an experimental programme is being carried out in parallel in the PANDA facility at the Paul Scherrer Institute and in the MISTRA facility at the Commissariat à l'Energie Atomique. Part of the program focuses on gas stratification break-up induced by mass sources and similar tests have been performed in both facilities. Indeed, the scaling effect of the phenomena involved in the erosion of a gas stratified layer can be assessed. Depending on the interaction Froude number, different regimes have been identified including pure diffusive mixing, global dilution or slow erosion processes. These phenomena are driven by different time scales. Small value of the non-dimensional number leads to mixing process driven by molecular diffusion. When the interaction Froude number is increased to large values, the dilution process can be described by a global time scale based on volumetric mixing provided that the air entrainment by the jet is taken into account. The intermediate case with two layers is more complicated and a single time scale cannot be derived. These test results with high-quality measurements can be regarded as a good basis for CFD models verification.
\end{abstract}

\section{INTRODUCTION AND MOTIVATIONS}

The presence of a stable light gas stratified layer in a PWR containment during the course of a severe accident is an important phenomenon for nuclear safety-related hydrogen hazard. The concentration inside this gas cloud can reach the flammability limits and the probability of occurrence of an hydrogen explosion can significantly increase. Consequently, the integrity of the containment would be threatened due to the generated overpressure and radioactive materials would be released into the environment. The conditions to obtain a stable stratified layer from a bottom-centred gaseous discharge in a closed vessel have already been addressed in the literature. The gas injection can be mainly described by two non-dimensional numbers: the Reynolds number $\mathrm{Re}_{0}$ and the Richardson number $\mathrm{Ri}_{0}$. In the following we assume that the injection Reynolds number is large enough to have a turbulent flow.

From the pioneer work of Morton et al. (1956) about jet entrainment, Baines et Turner (1969) described the different behaviour of an enclosure in case of plume release $\left(\boldsymbol{R} \boldsymbol{i}_{\boldsymbol{0}} \square \mathbf{1}\right)$. Qualitatively, the vertical density profile outside the rising flow pattern can be divided into two or three zones. If the inertia of the rising plume is small when the flow hits the top of the vessel, a linear density gradient is obtained from the top to the bottom. Otherwise, overturning can occur and a well-mixed region is created at the top with a linear density gradient below. If the Richardson number is further reduced, overturning can involve the whole enclosure and a homogeneous atmosphere is obtained. Cleaver et al. (1994) studied this phenomenon for a methane release in an enclosure and demonstrated that stable stratification did not occur if:

$$
R i_{0}<c^{2} \frac{R_{0}^{3}}{H^{2} V^{1 / 3}}
$$

Peterson (1994) developed a similar criterion with a slightly different constant c because of partially confined conditions. Finally, in the nuclear containment thermal-hydraulics issues, Andreani et al. (2008) illustrated the set-up of a stratified atmosphere with an horizontal steam jet.

Now, we consider that the stratified layer is already set-up inside the containment and a vertical air jet is coming from below. Baines (1975) studied the jet impingement on a density interface and showed that under certain conditions this interaction stops the forward motion of the turbulent fluid. The entrainment depends only on the characteristics of the jet as it impinges and on the density difference across the interface. Three parameters are necessary to quantify this phenomenon: the velocity $U$ and the diameter $L$ of the jet in the impingement region and $\mathrm{N}$, the characteristic pulsation of the stratification usually defined as (Jirka, 2004): 


$$
N=\sqrt{2 \mathrm{~g} \frac{\left(\rho_{a i r}-\rho_{s}\right)}{\left(\rho_{\text {air }}+\rho_{s}\right) H_{s}}}
$$

These parameters can be combined into one non-dimensional number called the interaction Froude number:

$$
F r=\frac{U}{N L}
$$

If this Froude number is lower than 1, buoyancy of the stratified layer dominates, and the air flow erodes the stratification without penetration. For large Froude number, the momentum dominates, and the air flow penetrates inside the stratification and when the whole stratified layer is involved in this process, the phenomenon is usually called dilution. The impact velocity of the air jet at the stratified layer can be obtained by the use of well-defined correlation of velocity decay along the centreline for free jets (Rodi, 1982):

$$
U=6.2 \mathrm{U}_{0} \frac{d_{0}}{\left(z-H_{0}\right)}
$$

The same reference provides the evolution of the jet diameter along the jet trajectory:

$$
\frac{L}{2}=0.086\left(z-H_{0}\right)
$$

To the authors' knowledge, the different regimes identified during this interaction were not deeply addressed experimentally and numerically in confined geometry. Difficulties of CFD containment thermal-hydraulics codes to predict the behaviour of a stratified layer in case of an injection from below was already demonstrated during the ISP 47 exercise (Allelein, 2007).

The present paper is devoted to the analysis of the common tests performed in PANDA and MISTRA facilities within the OECD/SETH-2 project to address the issue presented above. Simplified tests conditions were selected for this comparison. The tests involved only air and helium mixture. A stratified layer of air/helium mixture was created at the top of both facilities. Then, air was injected vertically from below in order to erode the layer and the transient of the mixing process was recorded with high spatial and temporal resolutions. The operating conditions were almost isothermal and at constant pressure. For comparison purpose, two tests, one at high interaction Froude number and a diffusion test have been selected at the PANDA scale whereas four tests (diffusion, low, moderate and high interaction Froude number) are considered at the MISTRA scale.

The main motivation of this work was also to compare both facilities for similar test conditions in order to assess the scaling effect and exhibit scaling parameters as erosion in these conditions is governed by nondimensional numbers.

After this introduction, the first section describes the facilities and the test conditions. Then, the results obtained are presented in the second section. Comparisons and discussions are addressed in the last section where non-dimensional analysis and scaling parameters are exhibited. Conclusions follow.

\section{FACILITIES AND TESTS CONDITIONS}

PANDA and MISTRA are large-scale thermal-hydraulics test facilities designed and used for investigating containment related phenomena for different Light Water Reactors designs (Auban, 2007 and Studer, 2007). Two main PANDA vessels (named Vessel 1 and 2) are used in the SETH-2 project to represent two compartments of a nuclear reactor containment. These two vessels having each a diameter of about $4 \mathrm{~m}$ and a height of $8 \mathrm{~m}$ are interconnected by a pipe of about 1 meter diameter. The vessel 1 (Figure 1 - right) is mainly used in the present experiments. MISTRA facility is a single vessel (Figure $1-$ left) with almost the same length scales ( $4.25 \mathrm{~m}$ inner diameter and a height of $7.4 \mathrm{~m}$ ). A compartment consisting of an inner cylinder with an annular floor located approximately at mid elevation was installed inside the main vessel.

Location of gas concentration sensors (sampling tubes for PANDA, sampling tubes and mini-katharometers for MISTRA) is reported on Figure 1. They were distributed along the stratified layer in both facilities. In the PANDA tests, measurements were conducted in the alignment of the air injection near the wall as well as 
in the central axis. In the MISTRA facility, the mini-katharometers and the injection were located in the annular ring not along the centreline of the facility. Three positions were available for the katharometers defined by their radius in $\mathrm{mm}$ and angle: $\left(1540,7.5^{\circ}\right),\left(1480,141^{\circ}\right)$ and $\left(1060,277.5^{\circ}\right)$. The air injection was located at $\left(1352,165^{\circ}\right)$.

The source of error of the concentration measurement is twofold. First, there is the uncertainty inherent to the calibration system and to the measurement, which leads in the present case of dry gas to a maximum uncertainty of $0.8 \%$ absolute in case of mass spectrometer in PANDA and $0.2 \%$ absolute with the minikatharometers in MISTRA. Second is the uncertainty inherent to the measurement itself. It depends on the stability of the system and on the time of recording. Once again, in case of dry gas and with a recording time of 5 seconds, the error is estimated to less than $0.2 \%$ of the average value for the mass spectrometer. For the mini-katharometers this contribution is one order of magnitude less than the previous one. Being conservative and considering the maximum measured helium molar fraction $(45 \%)$, we can estimate the maximum error to be about $0.9 \%$ absolute in PANDA and $0.2 \%$ in MISTRA.

The main test conditions are reported in Table 1 for both facilities. The boundary and initial conditions are almost the same except the distance between the injection location and the bottom of the stratified layer (2200 $\mathrm{mm}$ in the MISTRA test conditions and $875 \mathrm{~mm}$ in the PANDA test conditions). Slightly heated air was also injected in the PANDA experiments, whereas in MISTRA air at ambient temperature was injected.

Tab. 1: Initial and boundary conditions for PANDA and MISTRA tests

\begin{tabular}{|l|c|c|c|}
\hline Data & PANDA & MISTRA & Unit \\
\hline Injection diameter $\left(\mathrm{d}_{0}\right)$ & 75 & 72 & $\mathrm{~mm}$ \\
\hline Injection height $\left(\mathrm{H}_{0}\right)$ & 4013 & 3660 & $\mathrm{~mm}$ \\
\hline Elevation of the top of the facility $\left(\mathrm{H}_{\mathrm{F}}\right)$ & 8569 & 7379 & $\mathrm{~mm}$ \\
\hline Elevation of the bottom of the stratified layer $\left(\mathrm{Z}_{\mathrm{min}}\right)$ & 4875 & 5800 & $\mathrm{~mm}$ \\
\hline Height of the stratified zone $\left(\mathrm{H}_{\mathrm{s}}\right)$ & 1250 & 1300 & $\mathrm{~mm}$ \\
Total pressure & 0,974 & 1,005 & bar \\
\hline Temperature & 288 & 292 & $\mathrm{~K}$ \\
\hline Injected air flow $\left(\mathrm{Q}_{\text {air }}\right)$ & 15 & 4,5 to 50,6 & $\mathrm{~g} / \mathrm{s}$ \\
\hline Injected air temperature $\left(\mathrm{T}_{\text {air }}\right)$ & 303 & 292 & $\mathrm{~K}$ \\
\hline
\end{tabular}




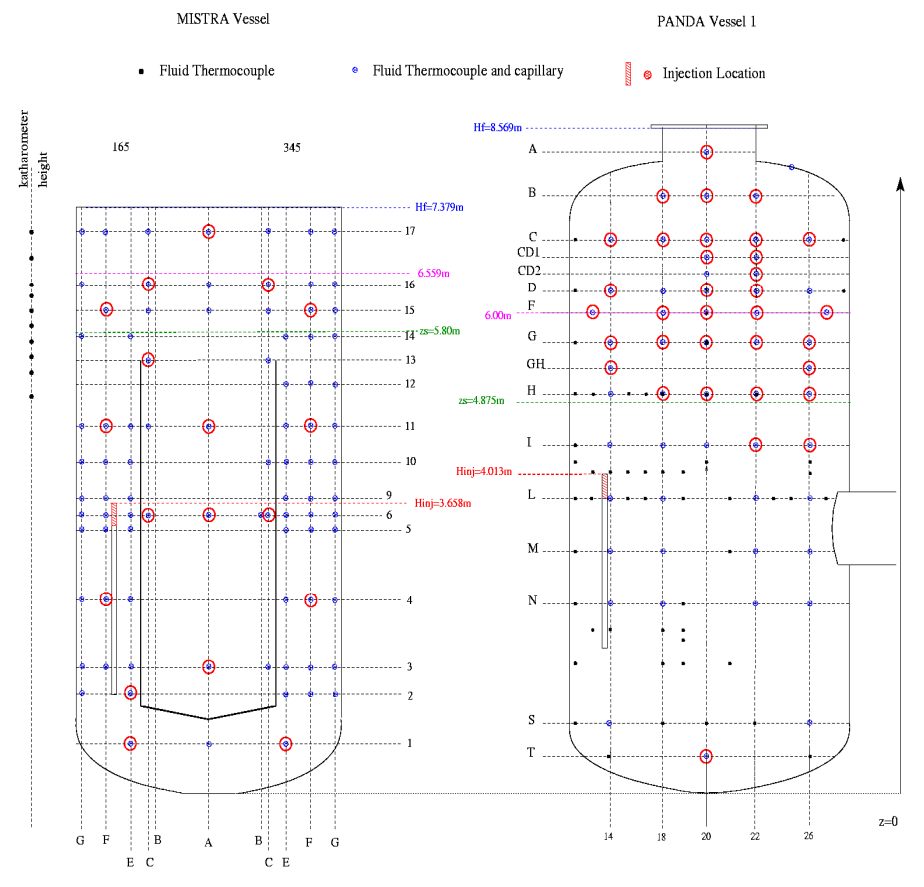

Fig. 1: View of MISTRA and PANDA facilities with sensors locations

The stratified layer of light gas in the top of both facilities is plotted in Figure 2. The shape is equivalent but the location is slightly different. Especially, the helium reservoir in the top of the facility is higher in the PANDA test.

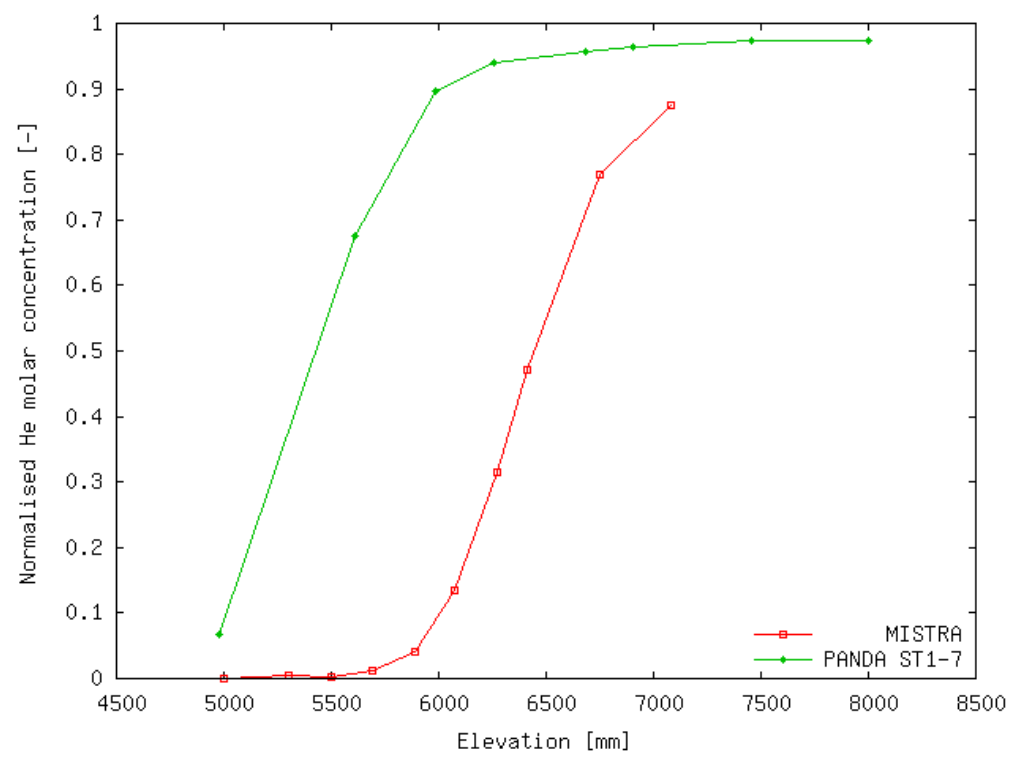

Fig. 2: Stratified layer at $\mathrm{t}=0$ in both facilities PANDA and MISTRA

Non-dimensional Froude number can be calculated based on the initial and boundary conditions of the tests (Table 2). According to the hypothesis of the calculations, the interaction Froude numbers cover a large range between 0.3 and 6. The PANDA test ST1-7 is more momentum dominated than the corresponding MISTRA test (LOWMA3). Nevertheless, due to the large helium reservoir at the top of PANDA facility, the penetration of the air jet can be limited to a certain extent and the global dilution of the stratified layer can not be achieved very quickly. A second Froude number $\left(\mathrm{Fr}_{2}\right)$ based on the interface gradient has been defined 
in order to take into account this reservoir effect:

$$
F r_{2}=\frac{U}{\sqrt{g \frac{\left(\rho_{s}-\rho_{\text {air }}\right)}{\rho_{\text {air }}}\left(H_{F}-Z_{\text {min }}\right)}}
$$

According to this new non-dimensional number, the PANDA ST1-7 test is between the MISTRA LOWMA3 and LOWMA4 tests and the latter corresponds to a Froude number close to unity recalling that inertia of the impinging jet is equivalent to the buoyancy of the stratified layer. It should be pointed out that this calculated Froude numbers are based on ideal initial conditions and that, for the duration of the test, it changes.

Tab. 2: Non-dimensional analysis for PANDA (ST1_7) and MISTRA (LOWMA series)

\begin{tabular}{|l|c|c|c|c|c|c|c|c|}
\hline Test & $\mathrm{Q}_{\text {air }}(\mathrm{g} / \mathrm{s})$ & $\mathrm{U}_{0}(\mathrm{~m} / \mathrm{s})$ & $\mathrm{U}(\mathrm{m} / \mathrm{s})$ & $\begin{array}{c}\mathrm{Z}_{\min }(\mathrm{m} \\
)\end{array}$ & $\mathrm{N}(\mathrm{Hz})$ & $\mathrm{L}(\mathrm{m})$ & $\mathrm{Fr}$ & $\mathrm{Fr}_{2}$ \\
\hline ST1_7 & 15,02 & 3,03 & 1,64 & 0,86 & 1,83 & 0,15 & 6,04 & 0,48 \\
\hline LOWMA2 & 4,53 & 0,93 & 0,19 & 2,14 & 1,75 & 0,37 & 0,30 & 0,08 \\
\hline LOWMA3 & 15,17 & 3,11 & 0,65 & 2,14 & 1,75 & 0,37 & 1,00 & 0,29 \\
\hline LOWMA4 & 50,58 & 10,36 & 2,16 & 2,14 & 1,75 & 0,37 & 3,35 & 0,96 \\
\hline
\end{tabular}

\section{PANDA AND MISTRA RESULTS}

Two tests were run in the PANDA facility named ST1-7 and ST1-7-2. An additional reference diffusion test has also been conducted for comparison with the initially conducted tests ST1-7 and ST1-7-2. Even though the initial concentrations were slightly different, the two tests ST1-7 and ST1-7-2 gave comparable results and only ST1-7 will be here compared to the corresponding diffusion test and the MISTRA results.

The diffusion test was conducted with both vessels isolated from environment for a period of three day and with the same initial distribution as in ST1-7 (Fig. 2). The time evolution of the helium molar fraction along the central axis is plotted in Figure 3. Only the first 25000 seconds are shown here. During the first 5000 seconds very little helium is diffused from the upper part of vessel 1 (Level A). This test should be compared with ST1-7 presented in Figure 4. During the process of mixing, well-mixed conditions are achieved up to a certain elevation that grows with time, from $5.6 \mathrm{~m}$ at $1000 \mathrm{~s}$ to $6.93 \mathrm{~m}$ at $12000 \mathrm{~s}$. The helium content in this well-mixed layer decreases with time due to the continuous dilution induced by the injected air. Two sensors located at the top of the facility (A and B) cannot reach these well-mixed conditions during the process of air injection. When the air injection is stopped (12500 seconds), a splitting of the gas concentration measurements in the layers below $6.93 \mathrm{~m}$ is observed. After the damping of the convection effect in the vessel, this would correspond once again to a pure diffusive process due to helium coming from above. 


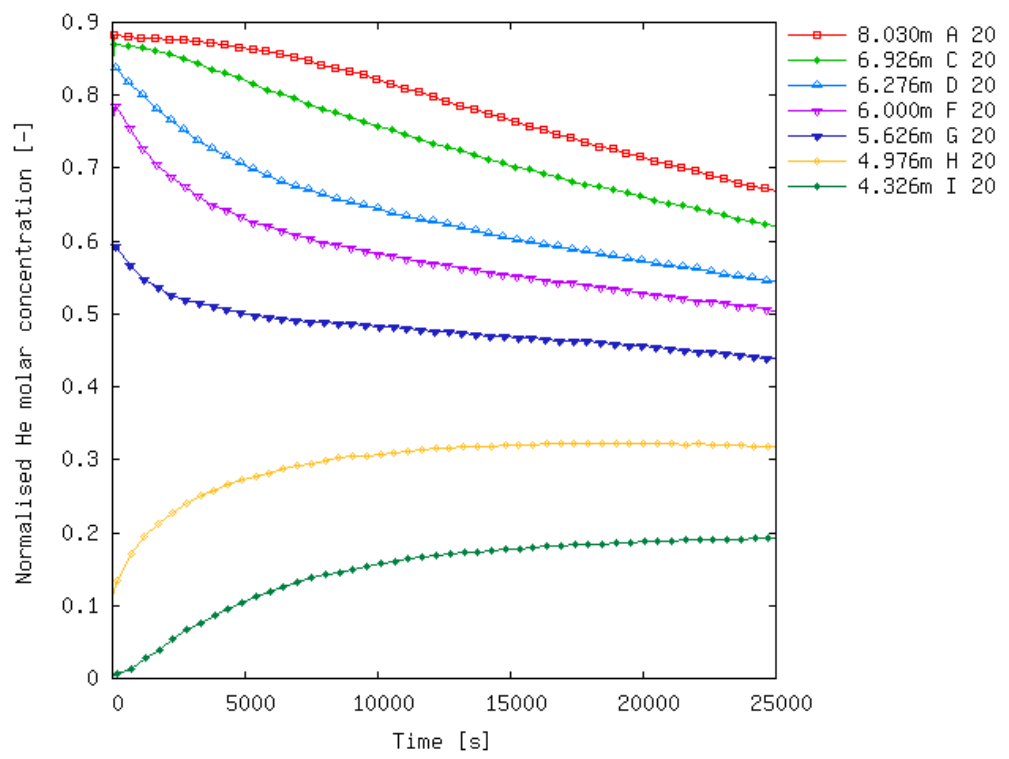

Fig. 3: Results of PANDA diffusion test - Helium concentration along the centreline versus time

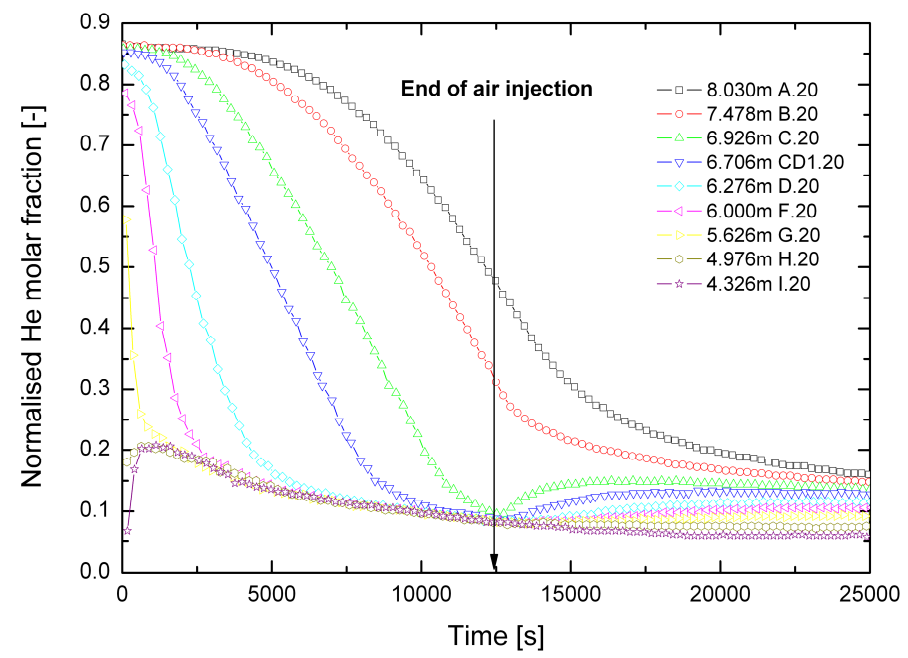

Fig. 4: Results of PANDA ST1-7 test - Helium concentration along the centreline versus time Both test can be compared by normalizing the helium molar fraction with the corresponding maximum value. Figure 5 clearly shows that the upper layers are initially governed by pure diffusive process. More than $5000 \mathrm{~s}$ of air injection are needed before that the helium concentration evolution deviates from the pure diffusion evolution. It is in the range of $2000 \mathrm{~s}$ for $\mathrm{C}$ level and around $300 \mathrm{~s}$ for the level $\mathrm{F}$. This means that the upper layer does not see the impact of the air jet until late in the experiment and that also, despite an initial Froude number larger than one, the air jet does not penetrate deeply in the layer initially. The effect of the impact of the jet on the layer can also be observed by comparing the helium concentration measurements along the air injection axis (denoted as 14 in PANDA nomenclature) and off axis (denoted 18, 20, 22 or 26 in PANDA nomenclature). For a given elevation, an earlier drop of the concentration along the injection axis is observed compared to the rest of the layer off injection axis. Also, the time at which the concentration along the injection axis departs from the others locations give information on the penetration depth of the air jet. For C level $\sim 10000 \mathrm{~s}$, for D level $\sim 3700 \mathrm{~s}$ and for F level $\sim 1500 \mathrm{~s}$. One final remark concerns the fact that the dilution process slows down for each level as soon as the jet has reached the corresponding level height, in other words, right after the departure time given previously. 


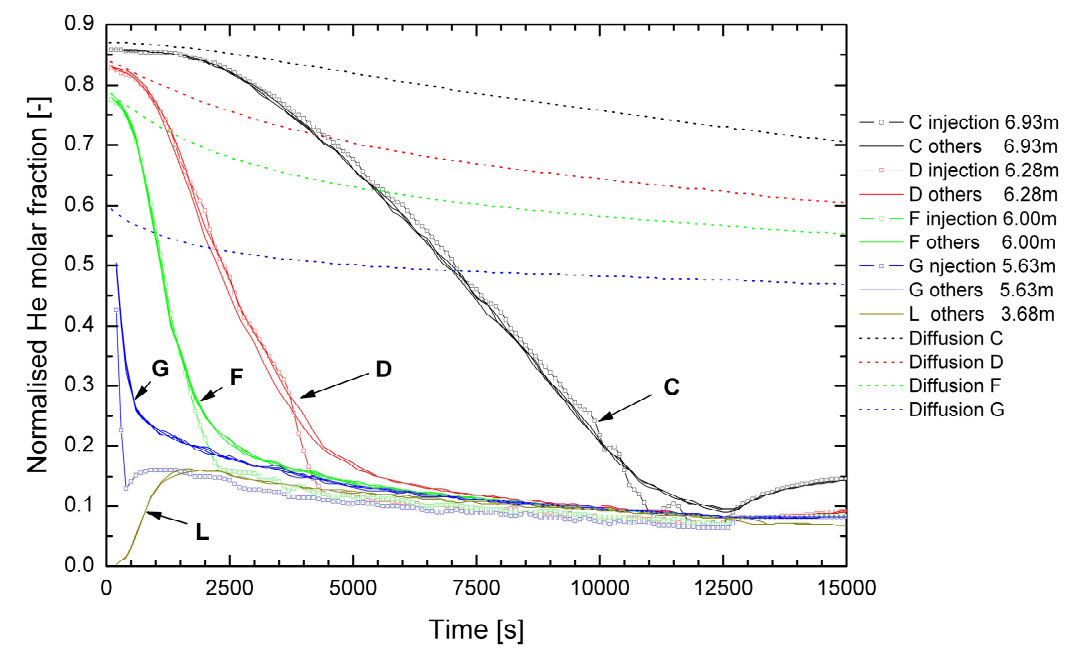

Fig. 5: Impact of air jet on the helium layer (PANDA ST1-7)

Different tests including reproducibility were performed in the MISTRA facility in order to follow the behaviour of the stratified layer created initially (Brinster, 2009). In the first experiment (diffusion test), no air injection was imposed and the erosion of the helium layer by diffusive process was recorded (Figure 6). The profiles are similar to those observed in the PANDA diffusion test and a good agreement is obtained with a 2D solution of pure molecular diffusion process performed with the CAST3M CFD computer code. In the simulation, the diffusion coefficient of helium in air is set to $6.9810^{-5} \mathrm{~m}^{2} / \mathrm{s}$ according to Marrero and Mason (1972).

When air is injected below the stratified layer, modification of the transient behaviour is expected. Nevertheless, if the air flow rate is small (LOWMA2 test) namely the interaction Froude number is small ( 0,3 in this case), the erosion of the stratified layer is still governed by the diffusion phenomena. There were no noticeable differences between LOWMA2 results and the diffusion results. In each LOWMA test, the air injection was stopped after 6000 seconds.

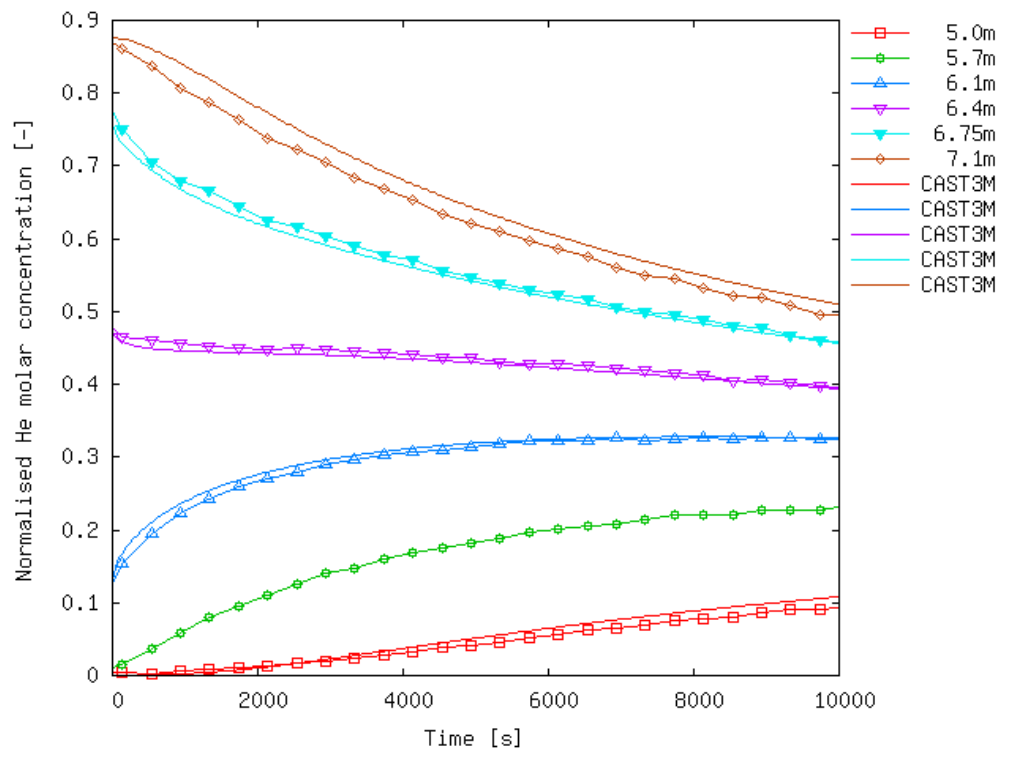

Fig. 6: Results of MISTRA diffusion test - Helium concentration

Large interaction Froude number leads to a rapid break-up of the stratified layer (Figure 7). Just after the beginning of air injection, the layers up to $6.75 \mathrm{~m}$ are impacted by the dilution process. The erosion of the upper layer $(7.1 \mathrm{~m})$ is first driven by the diffusion process during about 100 seconds and then dilution process involves the whole layer. Such delay has also been observed in the PANDA results (F level). 


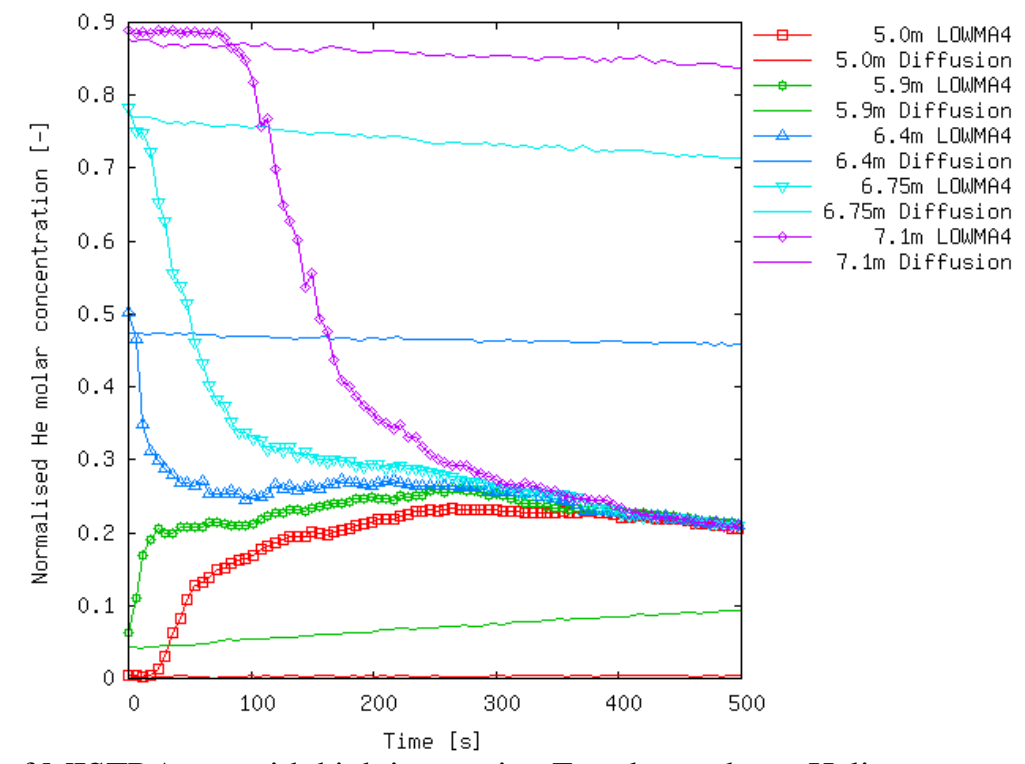

Fig. 7: Results of MISTRA test with high interaction Froude number - Helium concentration at (1540, $\left.7.5^{\circ}, \mathrm{z}\right)$

In the critical range $\mathrm{Fr} 1$, the injected air starts to dilute the lower layers of the air/helium cloud and then, the diffusion process is enhanced by this convective contribution. This clearly appears on Figure 8. It is also interesting to notice that due to the small depth of the air/helium cloud in the MISTRA facility, shorter delays in the behaviour of the upper layers are observed compared to the PANDA results. The sensors located around $6 \mathrm{~m}$ show first the effect of the injection and this is probably due to the off-centred injection and the off-centred location of the measurement devices. Then, sensors located below $6 \mathrm{~m}$ need some delay to reach almost well-mixed conditions. Above $6 \mathrm{~m}$, all the sensors especially at 6.1 and $6.25 \mathrm{~m}$ elevations record decreasing helium concentration due the dilution effect of the lower layers. At the end of the air injection (6000 seconds), the well-mixed conditions extend to $6.25 \mathrm{~m}$ and the upper part of the facility remains stratified.

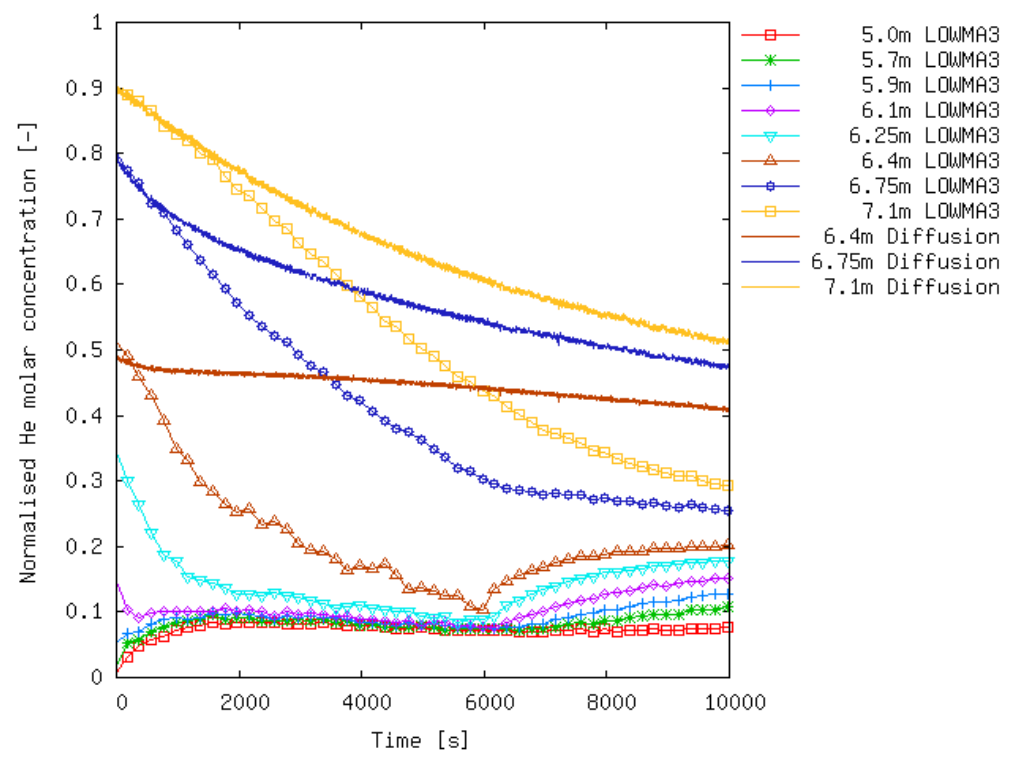

Fig. 8: Results of MISTRA LOWMA3 test with intermediate interaction Froude number - Helium concentration at $\left(1480,141^{\circ}, \mathrm{z}\right)$ 


\section{COMPARISON AND DISCUSSIONS}

\subsection{Local analysis}

Direct comparison of the measurements is difficult due to some differences listed previously (height of the injection line compared to the bottom of the stratified layer, slightly heated air jet, different depth of the stratified layer). Comparison between tests performed in both facilities requires non-dimensional quantities. Gas concentrations fulfil this requirement and characteristic time scales have to be defined. The time scale corresponding to homogenization by molecular diffusion of the gaseous volume inside the facility can be the first reference scale. The 2D CFD computations with CAST3M code have shown that the time scale assuming that $90 \%$ of the well-mixed conditions are achieved is almost the same in both facilities (about 200000 seconds). So, long term comparison can be directly performed and two sensors located in the diffusive region during LOWMA3 (6.4 and 7.1 m elevation) and ST1-7 tests (6.71 and $7.48 \mathrm{~m}$ elevation) show approximately the same transient behaviour.

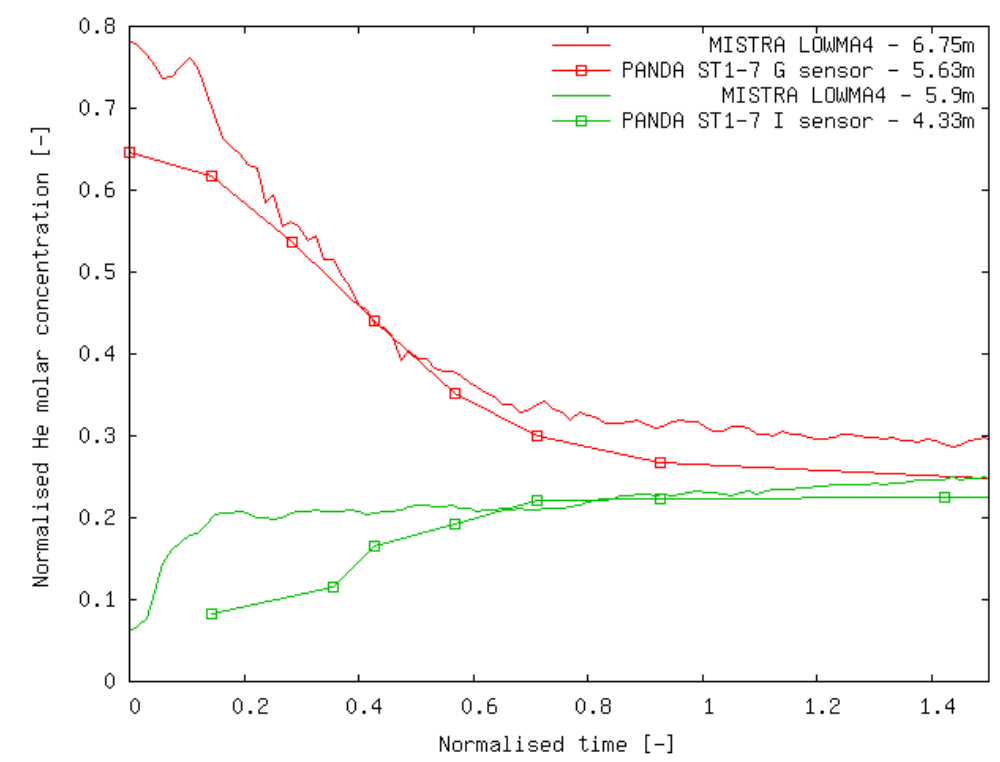

Fig. 9: Comparison for local Helium concentration and short time scale $\left(t^{*}=t / t_{\text {air }}\right)$

A second time scale can be derived from the initial and boundary conditions $t_{\text {air }}=\mathrm{V}_{\text {cloud }} / \mathrm{Q}_{(\mathrm{v}, \text { air })}$ where $\mathrm{V}_{\text {cloud }}$ is the equivalent volume of injected helium and $\mathrm{Q}_{(\mathrm{v}, \text { air }}$ is the volumetric flow of injected air. For the LOMWA3 and ST1-7 tests, the values of $t_{a i r}$ are 451 and 933 seconds respectively. The factor of 2 corresponds to the difference in the volume of helium stored at the top of the facility. For this short term analysis, the test LOWMA4 has been selected and the comparison is performed with the PANDA ST1-7 results. In these two tests, the interaction Froude number is high enough for the air jet to penetrate the stratified layer. Two sensors with approximately the same initial helium content has been chosen for comparison (Figure 9). The results seem to indicate that the selected time scale is the adequate reference time scale for short term behaviour (dilution dominated mixing process).

Finally, a third time scale corresponding to the departure from a pure diffusive process can be derived for the upper layers in the different tests (Figures 5, 7 and 8). This time is called $t_{\text {dep }}$ and Figure 10 summarizes the results. When $\mathrm{Fr}_{2}$ increases, the slope also increases indicating faster phenomenon and the PANDA results lie in between the two MISTRA results. 


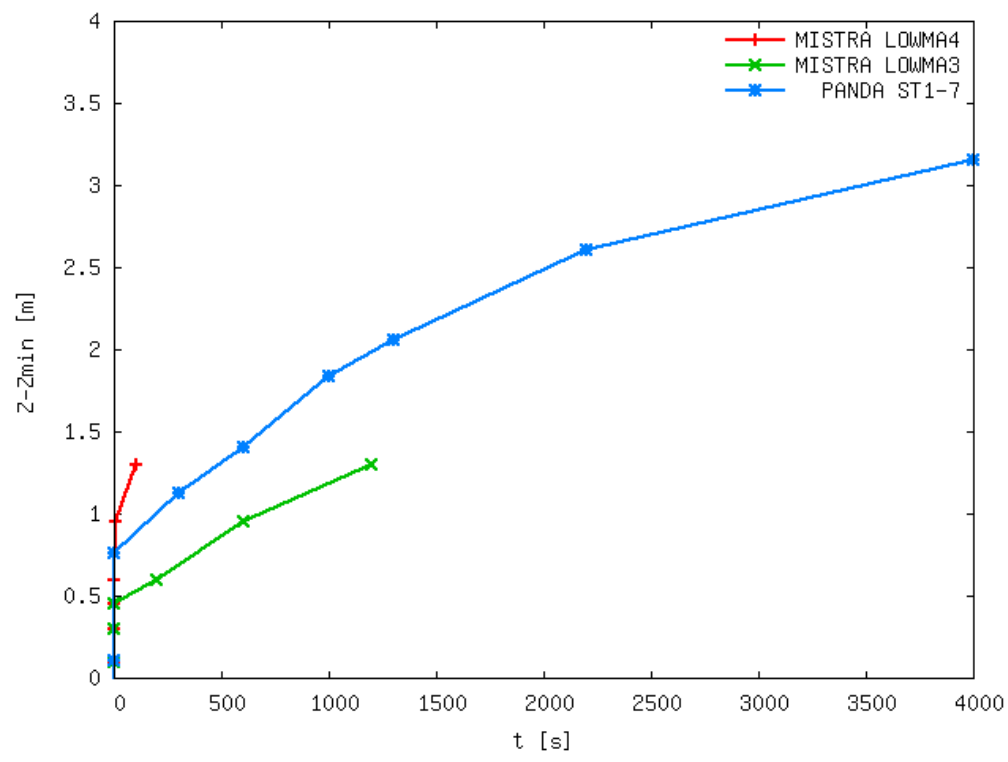

Fig. 10: Local analysis - departure time $\left(\mathrm{t}_{\mathrm{dep}}\right)$ from a pure molecular diffusive process at a given elevation

\subsection{Global analysis}

Let us define $Z_{\min }$ the elevation located at the bottom of the stratified layer. Above this elevation a certain amount of helium is initially stored. The gas cloud size can be represented by the global variable $\mathrm{V}_{\text {cloud }}$ which accounts for the volume of helium above $\mathrm{Z}_{\min }$. In our case it also corresponds to the volumetric equivalent of the injected mass of helium. The erosion effect of any phenomenon can be represented by the time evolution of $\mathrm{V}_{\text {cloud }}$. The objective is to decrease the volume beyond the flammability limits. This is a global criteria and then, the local flammable gas concentration has also to be decreased below the lower flammability limit.

The weakest phenomenon to drive the erosion process is the molecular diffusion. Helium is swept out the stratified layer and air diffuses inside slowly. Assuming axial symmetry, the time evolution of $\mathrm{V}_{\text {cloud }}$ due to molecular diffusion can be solved analytically. In the present document, we have used the CAST3M simulations already mentioned to compute the time evolution of this volume. A relative good agreement is obtained between the experimental results and the molecular diffusion computation (Figure 11) for the LOWMA2 and diffusion tests.

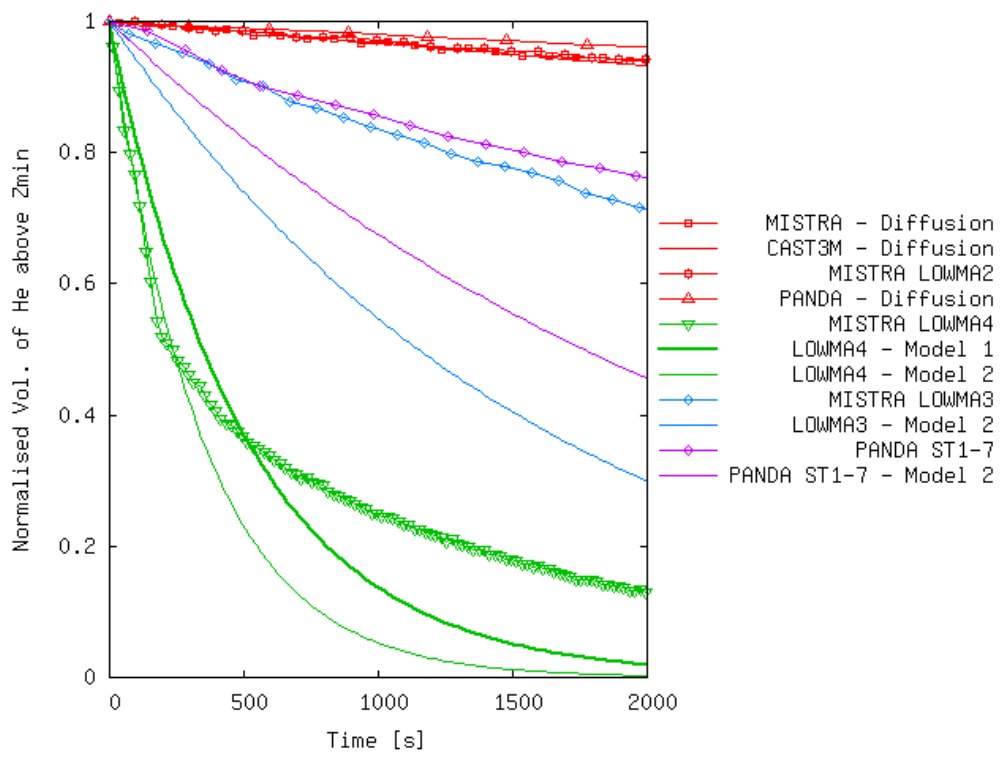

Fig. 11: Global analysis - evolution of the helium volume above $\mathrm{Z}_{\min }$ versus time

When air is injected from below, convection starts to play a significant role to the dilution or erosion process. 
The simplest way to model the air injection is to suppose that the whole layer is diluted by the entire air flow. This leads to well-mixed conditions and the volumetric balance of helium can simply be written as:

$$
\frac{d V_{\text {cloud }}}{d t}=-\frac{Q_{(v, \text { air })}}{V} V_{\text {cloud }}
$$

with the solution of:

$$
V_{\text {cloud }}(t)=V_{\text {cloud }}(\mathbf{0}) \exp \left(-\frac{Q_{(v, \text { air })}}{V} t\right)
$$

This first approach (called Model 1) is too simple because in the free jet theory, the volumetric flow is not conserved along the trajectory of the jet. Outside air/helium is entrained into the rising jet. The balance equation can be expressed as:

$$
\frac{d Q}{d s}=\alpha_{1} U \pi L
$$

with $\mathrm{L}$ the jet diameter, $\mathrm{U}$ the jet centreline velocity, $\mathrm{s}$ the coordinate along the trajectory and $\alpha_{1}$ the entrainment coefficient (0,055 for a pure jet). By the use of classical correlations (Eq. (4) and (5)) for the jet centreline velocity decay and the half-width growth, the air flow injected in the stratified layer can be estimated properly.

$$
\frac{d Q}{d s}=\alpha_{1}\left(6,2 U_{0} \frac{d_{0}}{s}\right) \pi 0,164 s=4,07 \alpha_{1} \frac{Q_{(v, a i r)}}{d_{0}}
$$

So, the volumetric flow of air increases linearly with $\mathrm{s}$ and depends only on the injection conditions. This last model (Model 2) is very close to the LOWMA4 experimental results at the beginning of the transient (Figure 11) where the slope is accurately captured. For the rest of the transient, since confined or semi-confined conditions are involved, helium is certainly entrained by the air jet and our simplified hypothesis are no longer valid. As a consequence, the time scale is longer in the experiments compared to the simplified models.

Between the two limiting cases, phenomena are more complex because the interaction of the rising jet and the stratified layer takes place at a certain level above $Z_{\min }$ and probably changes in time due to the erosion process. This is the case in the PANDA ST1-7 and MISTRA LOWMA3 tests where the behaviour of the erosion process is between pure diffusion and global dilution (Figure 11). The characteristic time scales proposed before are not accurate to compare both facilities from a global point of view. The two experimental curves are identical up to 500 seconds and then the deviation occurs: the ratio between the characteristic time scale of PANDA and MISTRA is about 1 for short time and 1.5 for long term. So, a single time scale cannot be derived for this global parameter.

\section{CONCLUSIONS AND PERSPECTIVES}

Interesting phenomena have been experienced in both PANDA and MISTRA facilities. Interaction of a fountain like flow with a stratified layer is a complex phenomenon. The different regimes including pure molecular diffusion mixing, global dilution and slow erosion process have been observed and analysed based on local and global behaviour. Dimensionless quantities have been proposed. The interaction Froude number can be used to identify the ability of the air jet to erode or to dilute the stratified layer. A second Froude number has been proposed to analyse the effect of the layer width. The Froude number has to be considered with care as it is calculated for initial condition only. It evolves with time leading to change in erosion process along the test and this is more true for PANDA due to the important helium reservoir on top of the facility. Regarding the time scale, small interaction Froude number leads to mixing process driven by molecular diffusion. When the interaction Froude number is increased to large values, the dilution process can be described by a global time scale based on volumetric mixing ( $\left.\mathrm{t}_{\text {air }}\right)$ provided that the air entrainment by the jet is taken into account. The intermediate case with two layers is more complicated and a single time scale cannot be derived. In consideration of the addressed complex phenomena and the non-trivial evolution of the dilution process, these tests results, and especially tests LOWMA3 in MISTRA and ST1-7 in PANDA can be regarded as a good database for CFD code verification. 


\section{ACKWNOWLEGMENTS}

The authors gratefully acknowledge the support of all the countries and the international organisations participating in the OECD/SETH-2 project. The authors would like to thank also the PANDA team and the MISTRA team for their support in conducting these experiments.

\section{REFERENCES}

H.J. Allelein, K. Fischer, J. Vendel, J. Malet, E. Studer, S. Schwarz, M. Houkema, H. Paillère, A. Bentaib, "International Standard Problem ISP-47 on Containment Thermal-hydraulics", NEA News 2007, 25.2 (2007).

M. Andreani, K. Haller, M. Heitsch, B. Hemström, I. Karppinen, J. Macek, J. Schmid, H. Paillère, I. Toth, "A benchmark exercise on the use of CFD codes for containment issues using best practice guidelines: A computational challenge", Nuclear Engineering and Design, 238, 502-513 (2008).

O. Auban, R. Zboray, D. Paladino, "Investigation of large-scale gas mixing and stratification phenomena related to LWR containment studies in the PANDA facility", Nuclear Engineering and Design, 237, 409-419 (2007).

W.D. Baines, J.S. Turner, "Turbulent buoyant convection from a source in a confined region", Journal of Fluid Mechanics, 37(1), 51-80 (1969).

W.D. Baines, "Entrainment by a plume or jet at a density interface", Journal of Fluid Mechanics, 68(2), 309-320 (1975).

J. Brinster, D. Abdo, E. Studer, I. Tkatschenko, J.L. Widloecher, "OECD/SETH-2 project: synthesis report for MISTRA INITIALA/LOWMA test", CEA technical report (2009).

R.P. Cleaver, M.R. Marshall, P.F. Linden, "The build-up of concentration within a single enclosed volume following a release of natural gas", Journal of Hazardous Materials, 36, 209-226 (1994).

G.H. Jirka, "Integral model for turbulent buoyant jets in unbounded stratified flows. Part I: single round jet", Environmental Fluid Mechanics, 4, 1-56 (2004).

T.R. Marrero, E.A. Mason, “Gaseous diffusion coefficients”, Journal of Physical Chemistry Reference Data, 1, 3-83 (1972).

B.R. Morton, S.G. Taylor, J.S. Turner, ”Turbulent gravitational convection from maintained and instantaneous sources", Proceedings of the Royal Society of London. Series A, Mathematical and Physical Sciences, 234, Issue 1196, 1-23 (1956).

P.F. Peterson, "Scaling and analysis of mixing in large stratified volumes", International Journal of Heat and Mass Transfer, 37(1), 97-106 (1994).

W. Rodi, Turbulent buoyant jets and plumes, Pergamon Press (1982).

E. Studer, J.P. Magnaud, F. Dabbene, I. Tkatschenko, "International Standard Problem on containment thermal-hydraulics ISP47: Step 1 - results of the MISTRA exercise", Nuclear Engineering and Design, 237, 536-551 (2007). 


\begin{tabular}{ll} 
NOMENCLATURE \\
$\mathrm{c}$ & Constant \\
$\mathrm{d}$ & Diameter \\
$\mathrm{Fr}$ & Froude Number \\
$\mathrm{g}$ & Gravity \\
$\mathrm{H}$ & Height \\
$\mathrm{L}$ & Length \\
$\mathrm{N}$ & Frequency \\
$\mathrm{Q}$ & Mass or volumetric flow \\
$\mathrm{R}$ & Radius \\
$\mathrm{Re}$ & Reynolds Number \\
$\mathrm{Ri}$ & Richardson Number \\
$\mathrm{s}$ & Curvilinear coordinate \\
$\mathrm{t}$ & Time \\
$\mathrm{T}$ & Temperature \\
$\mathrm{U}$ & Velocity \\
$\mathrm{V}$ & Volume \\
$\mathrm{z}$ or Z & Elevation \\
\hline
\end{tabular}

\section{Greek letters}

$\begin{array}{ll}\alpha & \text { Entrainment coefficient } \\ \rho & \text { Density }\end{array}$

\section{Subscript}

$\begin{array}{ll}0 & \text { Injection } \\ \text { air } & \text { Air } \\ \text { F } & \text { Refer to the facility } \\ \text { S } & \text { Refer to the stratified layer }\end{array}$

